\title{
Clinical Significance of Lymphoid Enhancer-Binding Factor 1 (LEF-1) Expression in Acute Myeloid Leukemia
}

\author{
Nahela Ahmed Shalaby, Doaa Ahmed Gamal Eissa, Botheina Ahmed Thabet Farweez, Shaimaa \\ Abdelmalik Pessar, Raghda EI Sayed Abdel Monem Galal
}

Department of Clinical Pathology Faculty of Medicine, Ain Shams University, Cairo, Egypt

\begin{abstract}
Background: Lymphoid enhancer-binding factor-1 (LEF1) is a member of the LEF/T-cell factor family of transcription factors and a key mediator of the Wingless-type (Wnt) pathway. It mediates Wnt signals through recruiting $\beta$-catenin and its co-activators to Wnt response elements of target genes. It plays crucial roles in normal hematopoiesis, not only in the development of $\mathrm{B}$ and $\mathrm{T}$ lymphocytes but also in granulopoiesis.

Objectives: The aim of this study was to evaluate of LEF1 expression levels in patients with AML and correlate this expression with clinical data.

Methodology: The present study was conducted on 30 de novo adult AML patients and 10 age and sex-matched controls with non-malignant hematological disorders (e.g.: hypersplenism, megaloblastic anemia, immune thrombocytopenic purpura) who attended Hematology/Oncology unit of Ain-Shams University Hospitals during the period from May 2017 till January 2018, after taking the approval of the Scientific and Ethical Committee of AinShams University. LEF1 expression levels were measured by quantitative real-time PCR.

Results: The present study showed that there was highly statistically significant association between patients and control group in LEF1 expression level. There was positive significant correlation between LEF1 expression level and $\mathrm{Hb}$ level and PLT count. While negative significant correlation was found with age, TLC count and peripheral blood blast \%. No correlation was found with bone marrow blasts \%. There was statistically significant difference between LEF1 expression level and both hepatosplenomegaly. No statistically significant difference was found between LEF1 expression level and Sex or lymphadenopathy.

Conclusion: Our study has shown that Lymphoid Enhancer-Binding Factor 1 (LEF-1) is over expressed in AML patients. LEF1 expression might be involved in the process of disease progression, and possibly can serve as a molecular parameter for risk assessment and/or monitoring of treatment in AML patients. Thus, molecular assessment of LEF1 expression at diagnosis may be of value to add to the prognostic work of AML patients.
\end{abstract}

Keywords: LEF1, Wnt, AML

\section{INTRODUCTION}

Acute myeloblastic leukemia (AML) is a clonal hematopoietic disorder characterized by uncontrolled self-renewal of hematopoietic stem cells, maturation arrest at myeloblast level, peripheral blood and bone marrow infiltration of blast cells ${ }^{(1)}$.

The AML is classified according to the World Health Organization (WHO) classification of tumors of hematopoietic and lymphoid tissues, which was last updated in 2008. The major categories of the current classification include AML with recurrent genetic abnormalities, AML with myelodysplasia-related changes, therapyrelated AML, and AML not otherwise specified ${ }^{(2)}$.

Researches are directed to describe the advances in the disease classification, understanding of the genomic landscape, identification of prognostic factors, current treatment, and new therapies under investigation in types of adult $\mathrm{AML}^{(3)}$.

Lymphoid enhancer-binding factor-1 (LEF1) is a member of the LEF/T-cell factor family of transcription factors and a key mediator of the Wingless-type (Wnt) pathway. It mediates Wnt signals through recruiting $\beta$-catenin and its coactivators to Wnt response elements of target genes. It plays crucial roles in normal hematopoiesis, not only in the development of B and T lymphocytes but also in granulopoiesis ${ }^{(4)}$.

The LEF1 controls neutrophilic granulopoiesis through direct activation of its target genes CCND1, MYC and BIRC5, encoding cyclin D1, c-myc and survivin, respectively. Reduced LEF1 expression plays a critical role in the defective maturation program of myeloid progenitors in individuals with severe congenital neutropenia ${ }^{(5)}$.

The Wnt pathway has been implicated in leukemic transformation and was shown to promote proliferation and survival of leukemic cells in vitro ${ }^{(6)}$. The LEF-1 was found to be highly expressed in different hematologic malignancies, including lymphomas, chronic lymphocytic leukemia, acute lymphocytic leukemia and $\mathrm{AML}^{(7)}$.

Increased expression of LEF1 affects normal expression of cell cycle and growthpromoting genes, such as cyclin D1 and c-myc and disturbs differentiation in hematopoiesis. Aberrant 
expression of LEF1 has been involved in solid cancers and leukemia ${ }^{(8)}$. The LEF1 is required for the growth of leukemia cells ${ }^{(9)}$.

The increase of LEF1 messenger ribonucleic acid (mRNA) and Wnt target gene cmyc was also shown in the blast phase of chronic myeloid leukemia. LEF1 has an oncogenic effect by promoting cell proliferation through regulation of target gene expression ${ }^{(10)}$.

AML-associated translocation products AML1-ETO and PML-RAR $\alpha$ encode aberrant transcription factors including those involved in the Wnt pathway. Activation of LEF dependent transcription has been demonstrated as a specific consequence of the presence of both fusion proteins. Aberrant LEF1 signaling could lead to increased growth and proliferation of myeloid progenitor cells through up-regulation of its target genes, such as c-myc and cyclin D1 ${ }^{(5)}$.

The human LEF-1 gene spans at least $140 \mathrm{~kb}$ and contains 12 exons and 11 introns, with a large third intron (about $75 \mathrm{~kb}$ ) that may contain an alternative exon. The LEF-1 gene encodes at least 2 isoforms. The LEF-1 is a sequence-specific deoxyribonucleic acid (DNA) binding protein that binds to a functionally important site in the T-cell receptor-alpha enhancer through a high mobility group (HMG) domain and confers maximal enhancer activity ${ }^{(6)}$.

Several investigations have indicated that high level of LEF1 predicts an adverse outcome in adult Bprecursor acute lymphoblastic leukemia ${ }^{(11)}$ and in chronic lymphocytic leukemia ${ }^{(12)}$. However, increased LEF1 level has been recently reported as a favorable prognostic marker in cytogenetically normal $\mathrm{AML}^{(8)}$.

The aim of this study was to evaluate of LEF1 expression levels in patients with AML and correlate this expression with clinical data.

\section{PATIENTS AND METHODS}

This study included a total of 30 de novo adult AML patients and 10 age and sex-matched controls with non-malignant hematological disorders (e.g.: hypersplenism, megaloblastic anemia, immune thrombocytopenic purpura) attending at Hematology/Oncology unit of Ain Shams University Hospitals. Approval of the ethical committee and a written informed consent from all the subjects were obtained. This study was conducted between May 2017 till January 2018.
All patients were subjected to: Full history taking. Thorough clinical examination, laying stress on the presence of extramedullary disease (hepatomegaly, splenomegaly, and lymphadenopathy). Laboratory investigations including: Complete blood picture using LH 750 cell counter (Coulter, Electronics, Hialeah, FL, USA) with examination of Leishman's stained PB smears. BM aspiration with examination of Leishman's stained BM smears. Cytochemical studies using Myeloperoxidase (MPO) stain. Immunophenotyping (IPT) on BM/PB samples by whole blood lysis performed on Coulter Navios flow cytometer (Coulter, Electronics, Hialeah, FL, USA). The results of cytogenetic studies were obtained from patients' files. Real-Time PCR for the detection of LEF1 mRNA expression levels.

Sampling: from each patient: Two $\mathrm{mL} P B$ samples were collected on $\mathrm{K}_{2}$-EDTA vacutainer tubes for performing CBC. About 4-5 ml BM aspirate were obtained and divided as follows: 0.5 to $1 \mathrm{~mL}$ was used for preparing smears stained with Leishman and MPO stains. Three $\mathrm{ml} \mathrm{BM}$ aspirate were divided into 2 K2-EDTA tubes for IPT and PCR (which were stored at $-80^{\circ} \mathrm{C}$ till performing RNA extraction). One $\mathrm{ml} \mathrm{BM}$ aspirate was obtained on lithium heparin for cytogenetic analysis.

Purification of total RNA, from whole blood: Total RNA was isolated from whole blood samples by using the "RNeasy Serum/Plasma Kit" (Qiagen, Hilden, Germany).

LEF1 expression levels were measured by quantitative real-time PCR.

\section{RESULTS}

Patient's ages showed a mean of $49.4 \pm 15$ years where 21 patients $(70 \%)$ were $\leq 60$ years and 9 patients $(30 \%)$ were $>60$ years. Seventeen $(56.7 \%)$ were males and $13(43.3 \%)$ were females. Out of the 30 studied AML patients, 12 patients (40\%) presented with hepatomegaly, 11 patients $(36.7 \%)$ presented with splenomegaly and 8 patients $(26.7 \%)$ presented with lymphadenopathy. The total leucocytic count (TLC) in the studied AML patients showed a median of $21 \times 10^{9} / \mathrm{L}$. The majority of the patients $23(76.7 \%)$ had TLC $<50$ x $10^{9} / \mathrm{L}$. Hemoglobin $(\mathrm{Hb})$ level showed a mean of $8.1 \pm 2.2$ $\mathrm{g} / \mathrm{dL}$. Most of the patients $24(80 \%)$ had Hb level $<10 \mathrm{~g} / \mathrm{dL}$. Platelet count showed a mean of $57.4 \pm$ $36.4 \times 10^{9} / \mathrm{L}$. The majority 26 patients $(86.7 \%)$ had 
PLT count $<100 \times 10^{9} /$ L. Peripheral blood blast cells $\%$ showed a mean of $36.8 \pm 26.8 \%$. The BM blasts $\%$ showed a mean of $72.9 \pm 20.6 \%$ (Table 1 ).

Our study group included 4 patients (13.3\%) M1, 13 patients (43.3\%) M2, 6 patients (20\%) M3, 5 patients (16.7\%) M4 and 2 patients (6.7\%) M5 (Table 2 ). At the end of the study, the fate of the patients was evaluated where 12 patients (40\%) were still alive and 18 patients $(60 \%)$ died (Table 3$)$. There was highly statistically significant difference between patients and control group in LEF1 expression level $(\mathrm{p}<0.001)$ as patients had higher expression level than control group with mean of $6.72 \pm 5.40 \log 10$ and $1.05 \pm 0.32 \log 10$, respectively (Table 4 ). There was positive significant correlation between LEF1 expression level and $\mathrm{Hb}$ level and PLT count. While negative significant correlation was found with age, TLC count and PB blast \%. No correlation was found with BM blasts \% (Table 5). There was statistically significant difference between LEF1 expression level and both hepatosplenomegaly. No statistically significant association was found between LEF1 expression level and Sex or lymphadenopathy (Table 6).

Table (1): Characteristic features of the AML patients.

\begin{tabular}{|c|c|c|c|}
\hline \multirow[t]{2}{*}{ Parameters } & \multicolumn{2}{|c|}{$\begin{array}{c}\text { Patients } \\
\mathrm{N}=30\end{array}$} & \multirow[t]{2}{*}{ Mean \pm SD or Median (IQR) } \\
\hline & $\mathbf{N}$ & $(\%)$ & \\
\hline $\begin{array}{l}\text { Age (years) } \\
\leq 60 \\
>60\end{array}$ & $\begin{array}{c}21 \\
9 \\
\end{array}$ & $\begin{array}{l}(70) \\
(30) \\
\end{array}$ & $49.4 \pm 15.0$ \\
\hline $\begin{array}{l}\text { Sex } \\
\text { Male } \\
\text { Female }\end{array}$ & $\begin{array}{l}17 \\
13\end{array}$ & $\begin{array}{l}(56.7) \\
(43.3)\end{array}$ & \\
\hline $\begin{array}{l}\text { Hepatomegaly } \\
\text { Yes } \\
\text { No }\end{array}$ & $\begin{array}{l}12 \\
18\end{array}$ & $\begin{array}{l}(40) \\
(60)\end{array}$ & \\
\hline $\begin{array}{l}\text { Splenomegaly } \\
\text { Yes } \\
\text { No }\end{array}$ & $\begin{array}{l}11 \\
19 \\
\end{array}$ & $\begin{array}{l}(36.7) \\
(63.3) \\
\end{array}$ & \\
\hline $\begin{array}{l}\text { Lymphadenopathy } \\
\text { Yes } \\
\text { No }\end{array}$ & $\begin{array}{c}8 \\
22\end{array}$ & $\begin{array}{l}26.7)( \\
(27.3)\end{array}$ & \\
\hline TLC (x 109/L) & & & $21(9.6-49.7)$ \\
\hline $\begin{array}{l}50 \geq \\
<50 \\
\end{array}$ & $\begin{array}{c}7 \\
23 \\
\end{array}$ & $\begin{array}{l}(23.3) \\
(76.7) \\
\end{array}$ & \\
\hline $\mathrm{Hb}(\mathrm{g} / \mathrm{dL})$ & & & $8.1 \pm 2.2$ \\
\hline $\begin{array}{l}10 \geq \\
<10\end{array}$ & $\begin{array}{c}6 \\
24 \\
\end{array}$ & $\begin{array}{l}(20) \\
(80)\end{array}$ & \\
\hline Platelets (x 1099/L) & & & $57.4 \pm 36.4$ \\
\hline $\begin{array}{r}100 \geq \\
<100 \\
\end{array}$ & $\begin{array}{c}4 \\
26 \\
\end{array}$ & $\begin{array}{l}(13.3) \\
(86.7) \\
\end{array}$ & \\
\hline PB blast $(\%)$ & - & - & $36.8 \pm 26.8$ \\
\hline BM blast $(\%)$ & - & - & $72.9 \pm 20.6$ \\
\hline
\end{tabular}

$\mathrm{N}=$ number; TLC: total leucocytic count; Hb: hemoglobin; PB: Peripheral blood; BM: bone marrow
Table (2): FAB classifications of AML patients.

\begin{tabular}{|l|l|c|c|}
\hline \multicolumn{2}{|c|}{ Parameters } & \multicolumn{2}{c|}{ Patients } \\
\cline { 3 - 4 } & M1 & N & \% \\
\cline { 2 - 4 } \multirow{4}{*}{$\begin{array}{l}\text { FAB } \\
\text { subtypes }\end{array}$} & M2 & 4 & $13.3 \%$ \\
\cline { 2 - 4 } & M3 & 13 & $43.3 \%$ \\
\cline { 2 - 4 } & M4 & 6 & $20.0 \%$ \\
\cline { 2 - 4 } & M5 & 5 & $16.7 \%$ \\
\hline
\end{tabular}

Table (3): Fate of the studied AML patients.

\begin{tabular}{|c|c|c|c|}
\hline \multirow{2}{*}{\multicolumn{2}{|c|}{ Parameters }} & \multicolumn{2}{|c|}{ Patients } \\
\hline & & $\overline{\text { Mean / N }}$ & SD / \% \\
\hline \multirow{2}{*}{ Fate } & Alive & 12 & $\% 40.0$ \\
\hline & Died & 18 & $60.0 \%$ \\
\hline
\end{tabular}

Table (4): Comparison between LEF1 expression level between AML patients and control.

\begin{tabular}{|l|c|c|c|c|c|}
\hline Parameter & $\begin{array}{c}\text { patients } \\
(\mathbf{n = 3 0})\end{array}$ & $\begin{array}{c}\text { Controls } \\
(\mathbf{n = 1 0})\end{array}$ & $\begin{array}{c}\text { Test } \\
\text { of } \\
\text { sig. }\end{array}$ & P value & Sig. \\
\hline $\begin{array}{l}\text { LEF1 } \\
(\log 10), \\
\text { mean } \pm \text { SD }\end{array}$ & $\begin{array}{c}6.72 \pm \\
5.40\end{array}$ & $\begin{array}{c}1.05 \pm \\
0.32\end{array}$ & $\begin{array}{c}\mathrm{t}= \\
5.71\end{array}$ & $\begin{array}{c}\mathrm{P}< \\
0.001(\mathrm{~T})\end{array}$ & $\mathrm{HS}$ \\
\hline
\end{tabular}

LEF1: lymphoid enhancer binding factor 1 ; $\mathrm{T}$ : $\mathrm{t}$ test; sig: significance; HS: highly significant

\section{$\operatorname{LEF} 1\left(\log ^{10}\right)$, mean}

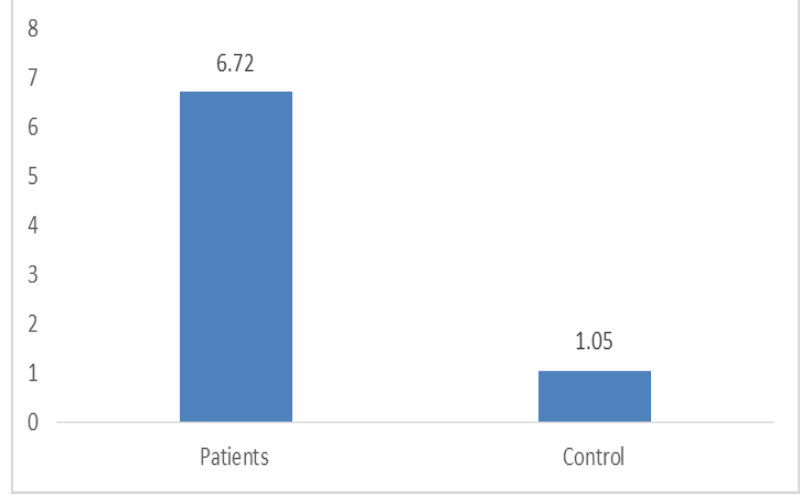

Figure (1): Comparison between LEF1 expression in patients and the control group.

Table (5): Correlation between LEF1 expression level and age and laboratory data.

\begin{tabular}{|l|c|c|c|}
\hline \multirow{2}{*}{\multicolumn{1}{|c|}{ Parameters }} & \multicolumn{3}{|c|}{ LEF1 expression level } \\
\cline { 2 - 4 } & Test of significance & P value & Sig. \\
\hline Age $($ years $)$ & $\mathrm{r}=-0.690$ & $<0.001$ & $\mathrm{HS}$ \\
\hline $\mathrm{Hb}(\mathrm{g} / \mathrm{dL})$ & $\mathrm{r}=0.686$ & $<0.001$ & $\mathrm{HS}$ \\
\hline $\mathrm{TLC}\left(\mathrm{x} 10^{9} / \mathrm{L}\right)$ & $\mathrm{r}=-0.644$ & $<0.001$ & $\mathrm{HS}$ \\
\hline $\mathrm{PLT}\left(\mathrm{x} 10^{9} / \mathrm{L}\right)$ & $\mathrm{r}=0.828$ & 0.001 & $\mathrm{HS}$ \\
\hline PB blast $\%$ & $\mathrm{r}=-0.593$ & $<0.001$ & $\mathrm{HS}$ \\
\hline BM blast $\%$ & $\mathrm{r}=0.007$ & 0.971 & $\mathrm{NS}$ \\
\hline
\end{tabular}

$\mathrm{Hb}$ : hemoglobin; TLC: total leucocytic count; $\mathrm{PB}$ : peripheral blood; BM: bone marrow; LEF1: lymphoid enhancer binding factor 1; r: Pearson correlation test;; sig: significance; HS: highly significant; $S$ : significant. 
Table (6): The relationship between LEF1 expression level and sex and clinical data among patients.

\begin{tabular}{|c|c|c|c|c|c|c|}
\hline \multirow{2}{*}{\multicolumn{2}{|c|}{ Parameters }} & \multirow{3}{*}{$\begin{array}{c}\text { Mean } \\
6.28\end{array}$} & \multirow{3}{*}{$\frac{\text { SD }}{5.12}$} & \multicolumn{3}{|c|}{ t test } \\
\hline & & & & $\bar{t}$ & p value & sig. \\
\hline \multirow{2}{*}{ Sex } & Male & & & & \multirow{2}{*}{0.618} & \multirow{2}{*}{ NS } \\
\hline & Female & 7.29 & 5.91 & & & \\
\hline \multirow{2}{*}{ Hepatomegaly } & No & 9.00 & 4.87 & \multirow{2}{*}{3.286} & \multirow{2}{*}{0.003} & \multirow{2}{*}{ HS } \\
\hline & Yes & 3.28 & 4.35 & & & \\
\hline \multirow{2}{*}{ Splenomegaly } & No & 8.22 & 5.07 & \multirow{2}{*}{2.115} & \multirow{2}{*}{0.043} & \multirow{2}{*}{$\mathrm{S}$} \\
\hline & Yes & 4.12 & 5.16 & & & \\
\hline \multirow{2}{*}{ Lymphadenopathy } & No & 6.94 & 5.24 & \multirow{2}{*}{0.374} & \multirow{2}{*}{0.711} & \multirow{2}{*}{ NS } \\
\hline & Yes & 6.10 & 6.15 & & & \\
\hline
\end{tabular}

NS: non significant; HS: highly significant: S: significant.

\section{DISCUSSION}

Acute myeloid leukemia is a heterogeneous hematological malignancy characterized by the clonal expansion of myeloid blasts in the peripheral blood, bone marrow and/or other tissues ${ }^{(12)}$. Although advances in supportive care and prognostic risk stratification have optimized established therapies, overall long-term survival remains poor ${ }^{(13)}$.

The diagnosis of AML mainly depends on the features of morphology, immunology, cytogenetics and molecular biology. Cytogenetic alterations provide most powerful information for the prognosis of AML and have been applied to guide treatment. Recently, molecular biological changes including gene mutations and abnormal gene expression profiles have also been found to play vital roles in leukemogenesis and predict response to therapy and survival ${ }^{(14)}$.

Lymphoid enhancer binding factor 1 is an important member of the LEF/ T-cell factor of transcription factors family. It has an important role in cellular proliferation and cell cycle regulation. It is traditionally regarded as a central mediator of the Wnt/ $\beta$ catenin signaling pathway. In addition, it has vital function in early hematopoiesis and leukemic transformation in murine models ${ }^{(15)}$.

It is well established that the $\mathrm{Wnt} / \beta$ catenin pathway controls the proliferation, survival and differentiation of hematopoietic cells. Continuous stimulation of Wnt signaling results in the neoplastic transformation of myeloid and lymphoid lineages. Physiologically the pathway is regulated strictly ${ }^{(16)}$. In healthy cells $\beta$ catenin levels are tightly controlled by secreted and/or intracellular located inhibitory proteins. Wnt signaling pathway aberrations triggering the increase of $\beta$ catenin levels, lead to the uncontrolled activation of the Wnt signaling pathway which has been reported in a number of malignancies especially hematological malignancies indicating that it may serve as a target of anti-tumor therapy ${ }^{(17)}$.

Lymphoid enhancer binding factor 1 was found to have a critical role in myeloid differentiation which has recently been reported in human model studies supported by the observation that in normal conditions mRNA levels of LEF1 reaches its maximum levels in the promyelocytic stage of differentiation and experiences reduction in the final granulocytic stage. Alteration of LEF1 expression have been identified to be associated with AML and lymphomas ${ }^{(18,19,4,10)}$.

Accordingly, the aim of this study was to evaluate of LEF1 expression levels in patients with AML and correlate this expression with clinical data.

The present study was conducted on 30 de novo adult AML patients and 10 age and sexmatched controls with non-malignant hematological disorders who attended the Hematology/Oncology unit of Ain-Shams University Hospitals during the period from May 2017 till January 2018.

LEF1 expression levels were measured by quantitative real-time PCR which has become a routine technique in most diagnostic laboratories and therefore easy to use in clinical applications. This was supported by ${ }^{(20,8,5,21,22,18)}$.

In our study we found that the expression levels of LEF1 were significantly higher in AML patients than in control group which could be attributed to the fact that aberrant LEF1 signaling leads to increased growth and proliferation of myeloid progenitor cells through up regulation of its target genes such as c-myc and cyclin $\mathrm{D} 1^{(23)}$. These findings were in accordance with previous studies of ${ }^{(20,8,5,22)}$.

But this finding was contradictory with Salarpour et al. ${ }^{(18)}$ who studied 96 patients in Iran found that LEF1 gene expression was significantly lower in patients with AML in comparison with the normal control group and attributed that to LFE1 gene in leukemic cells acts as a tumor suppressor gene. So, its reduction of expression allows leukemic cells to proliferate and increase in growth. Since this gene is a transcription factor important in the granulocytic differentiation thereby reduction of LEF1 expression may participate in the differentiation block in AML blasts which shows an increase in blast percentage and white blood cells. 
This discrepancy could be explained by the different ethnic, genetic or age background of the studied patients or may be different control group in different studies. This highlight the need for further larger study.

To evaluate the role of LEF1 overexpression in our group of patients, we investigated the significance of its expression in relation to various clinical and laboratory data and found that in clinical relation, there was significant negative correlation between LEF1 expression level and age where younger age patients had higher LEF1 expression level. These data were in agreement with Albano et $\boldsymbol{a l}{ }^{(21)}$ who found that the high LEF1 expression group showed a trend toward a statistically significant association with a lower median age.

Hepatosplenomegaly was significantly more encountered in patients with lower LEF1 mean expression patients. This may be due to high incidence of disease progression and lower treatment outcome in patients with lower LEF1 expression levels. This was consistent with Elhoseiny and Abdelfattah, ${ }^{(22)}$ who reported that hepatosplenomegaly was more represented in low LEF1 expression patients compared to high LEF1 expressors and the difference was statistically significant. The other previous studies in AML ${ }^{(8,5)}$ didn't report if there was an association between hepatosplenomegaly and LEF1 expression levels.

Concerning the laboratory data, our study found significant negative correlation between LEF1 expression level and TLC where patients with higher mean LEF1 expression level had lower TLC. Our results are in accordance with Metzeler et al. ${ }^{(8)}$ who studied $210 \mathrm{CN}$-AML patients and also with Albano et al. ${ }^{(21)}$ who studied LEF1 expression in 78 adult APL patients.

Our study detected a significant positive correlation between LEF1 expression level and $\mathrm{Hb}$ level and PLT count. These results were in accordance with Metzeler et al. ${ }^{(8)}$ and Elhoseiny and Abdelfattah (22) who found higher platelet counts in patients with higher mean LEF1 expression. This could be attributed to the good prognostic indication of the high LEF1 expression.

Finally, we found that our results are of particular interest because LEF1 is an important downstream effector of Wnt signaling, a pathway that is required for self-renewal of normal hematopoietic and leukemic stem cells ${ }^{(24)}$. This pathway had been found to be induced by several leukemogenic fusion genes and gene mutations in AML patients and also, aberrant activation of the Wnt effector $\beta$ catenin has been detected in primary AML samples. Thus LEF1 expression could be a potential new prognostic factor and target for therapy as small molecule Wnt pathway inhibitors were found to be cytotoxic for AML blasts ${ }^{(25)}$.

\section{CONCLUSION}

Our study has shown that Lymphoid Enhancer-Binding Factor 1 is over expressed in AML patients. LEF1 expression might be involved in the process of disease progression, and possibly can serve as a molecular parameter for risk assessment and/or monitoring of treatment in AML patients. Thus, molecular assessment of LEF1 expression at diagnosis may be of value to add to the prognostic work of AML patients.

\section{RECOMMENDATIONS}

To consolidate our results, we should recruit more patients to the study and follow them up for longer duration. More extensive larger cohort studies to evaluate the potential value of LEF1 mRNA over expression in the prognosis and monitoring of minimal residual disease of AML. Correlate LEF1 gene expression with other prognostic genes as mutations of NPM1, CEBPA and FLT3. It will also be interesting to investigate its relations with other known prognostic genes especially in CN-AML using larger patient populations. Consider LEF1 over expression as a therapeutic target when introducing LEF1 inhibitors along with conventional chemotherapy in treatment of AML patients.

\section{REFERENCES}

1- Ghasemi A, Ghotaslou A, Mohammadi M, Abbasian $S$ and Ghaffari $K$ (2016): Methylation of the Wnt signaling antagonist, Wnt inhibitory factor 1 and Dickkopf-1 genes in acute myeloid leukemia at the time of diagnosis. Zahedan J Res Med Sci., X: 29-33.

2- Swerdlow S, Campo E, Pileri S, Harris N, Stein H, Siebert R, Advani R, Ghielmini M, Salles G, Zelenetz A, Jaffe E (2016): The 2016 revision of the World Health Organization (WHO) classification of lymphoid neoplasms. Blood, 1-50. 
3- Döhner H, Weisdorf DJ and Bloomfield CD (2015): Acute myeloid leukemia. New England Journal of Medicine, 373: 1136-1152.

4- Jia M, Zhao H, Shen H, Cheng YP, Luo ZB, Li SS, Zhang JY and Tang YM (2015): Over expression of lymphoid enhancer-binding factor-1 (LEF1) is a novel favorable prognostic factor in childhood acute lymphoblastic leukemia. Int Jnl Lab Hem., 37: 631-640.

5- Fu Y, Zhu H, Wu W, Xu J, Chen T, Xu B, Qian S, Li J and Liu P (2014): Clinical significance of lymphoid enhancer-binding factor 1 expression in acute myeloid leukemia. Leukemia \& Lymphoma,55: 371-377.

6- Aly $R$ and Yousef A (2015): Prognostic significance of lymphoid enhancer binding factor-1 expression in Egyptian adult B-acute lymphocytic leukemia patients. Turk J Hematol., 32:15-20.

7- Gutierrez A, Sanda T, Ma W, Zhang J, Grebliunaite R, Dahlberg S, Neuberg D, Protopopov A, Winter SS, Larson RS and Borowitz MJ (2010): Inactivation of LEF1 in T-cell acute lymphoblastic leukemia. Blood, 115: 2845-2851.

8- Metzeler K, Heilmeier B, Edmaier K, Rawat VP, Dufour A, Döhner K, Feuring-Buske M, Braess J, Spiekermann K, Büchner $T$ and Sauerland MC (2012): High expression of lymphoid enhancer-binding factor-1 (LEF1) is a novel favorable prognostic factor in cytogenetically normal acute myeloid leukemia. Blood,120: 2118- 2126.

9- Zhou $F$, Zhang $L$, van $T$, van Dam $H$ and ten Dijke P (2011): GSK3beta inactivation induces apoptosis of leukemia cells by repressing the function of c-Myb. Mol Biol Cell,22: 35333540.

10-Guo X, Zhang R, Liu J, Li M, Song C, Dovat S, Li J and Ge Z (2015): Characterization of LEF1 high expression and novel mutations in adult acute lymphoblastic leukemia. PLoS One, 10: 1-13.

11-Erdfelder F, Hertweck M, Filipovich A, Uhrmacher $S$ and Kreuzer $K$ (2010): High lymphoid enhancer-binding factor-1 expression is associated with disease progression and poor prognosis in chronic lymphocytic leukemia. Hematol Rep., 2: 24-27.

12-O'Donnell MR, Tallman MS, Abboud CN, Altman JK, Appelbaum FR, Arber DA,
Attar E, Borate U, Coutre SE, Damon LE and Lancet J (2017): Acute myeloid leukemia, version 3.2017, NCCN clinical practice guidelines in oncology. Journal of the National Comprehensive Cancer Network, 15: 926-957.

13-De Kouchkovsky I and Abdul-Hay M (2016): Acute myeloid leukemia: a comprehensive review and 2016 update. Blood cancer journal, 6: $1-10$.

14-Li X, Guo H, Zhou J, Wu D, Ma J, Wen X, Zhang W, Xu Z, Lin J and Jun Q (2018): Overexpression of CTNNB1: Clinical implication in Chinese de novo acute myeloid leukemia. Pathology-Research and Practice, 3: 361-367.

15-Chen C, Huang X, Wang K, Chen K, Gao D and Qian S (2018): Early mortality in acute promyelocytic leukemia: Potential predictors. Oncology letters, 15: 4061-4069.

16-Pehlivan M, Caliskan C, Yuce Z, Sercan H (2017): Forced expression of Wnt antagonists sFRP1 and WIF1 sensitizes chronic myeloid leukemia cells to tyrosine kinase inhibitors. Tumor Biology, 39: 1-9.

17-Pehlivan M, Çalışsan C, Yüce $Z$ and Sercan H (2018): Secreted Wnt antagonists in leukemia: A road yet to be paved. Leukemia research, 69: 24-30.

18-Salarpour F, Goudarzipour K, Mohammadi M, Khosravi M, Salari S, Faraahi $S$ and Farsani M (2018): Transcription factors LEF1, PU. 1 and IRF8 have decreased expression levels in majority of de novo acute myeloid leukemia patients. Middle East Journal of Family Medicine, 10: 207-217.

19-Janovská $P$ and Bryja $V$ (2017): Wnt signalling pathways in chronic lymphocytic leukaemia and B-cell lymphomas. British journal of pharmacology,174: 4701-4715.

20-Fu Y, Zhu H, Wu W, Xu J, Shen W, Xu W, Liu $P$ and Li J (2012): The Expression of LEF1 Gene and its Clinical Significance in Chinese Patients with Acute Myeloid Leukemia. Blood, 4621.

21-Albano F, Zagaria A, Anelli L, Orsini P, Minervini CF, Impera L, Casieri P, Coccaro N, Tota G, Brunetti $C$ and Minervini A (2014): Lymphoid enhancer binding factor-1 (LEF1) expression as a prognostic factor in adult acute promyelocytic leukemia. Oncotarget, 5: 649-658. 
22-Elhoseiny $S$ and Abdelfattah $R$ (2016): Overexpression of lymphoid enhancer binding factor-1 (lef1) predicts Favorable outcome in cytogenetically normal acute myeloid leukemia (CN-AML). International Journal of Advanced Research, 4: 1532-1547.

23-Zarkou V, Galaras A, Giakountis A and Hatzis P (2018): Crosstalk mechanisms between the WNT signaling pathway and long non-coding RNAs. Non-coding RNA Research,3: 42-53.
24-Wang Y, Krivtsov A, Sinha A, North T, Goessling W, Feng Z, Zon $L$ and Armstrong S (2010): The Wnt/beta-catenin pathway is required for the development of leukemia stem cells in AML. Science, 327: 1650-1653.

25-Minke K, Staib P, Puetter A, Gehrke I, Gandhirajan R, Schlösser A, Schmitt E, Hallek $M$ and Kreuzer $K$ (2009): Small molecule inhibitors of WNT signaling effectively induce apoptosis in acute myeloid leukemia cells. Eur J Haematol., 82: 165-175. 